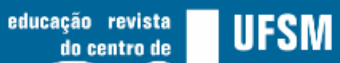

\section{Testes ABC no contexto da Escola Ipiranga/RS: pressupostos teóricos e cotidiano escolar}

\author{
ABC Tests in the context of the School Ipiranga/RS: theoretical and daily \\ assumptions of school practice
}

Renata dos Santos Alves

Universidade Federal de Pelotas

Carmo Thum

Universidade Federal do Rio Grande

\section{RESUMO}

O presente escrito objetiva compreender quais os sentidos e significados atribuídos pela professora da instituição à presença dos Testes $A B C$ no contexto da Escola Ipiranga, e a partir disso empreender problematizações acerca dos pressupostos teóricos do movimento escolanovista, dos Testes $A B C$ e da aplicabilidade de tal metodologia no contexto da Escola Ipiranga/RS. Para tanto, utilizaram-se como fontes de análise o livro "Testes $A B C$ : para a verificação da maturidade necessária à aprendizagem da leitura e da escrita", documentos de escrituração escolar e dados relativos a narrativas da professora que atuava na instituição no período analisado. Os testes apontam uma concepção de educação como conjunto de técnicas necessárias para a adaptação às exigências da nação. A incoerência da presença dos Testes $A B C$ na escola em estudo indica resistências a partir de práticas ressignificadas e evidencia a ausência da relação entre pressupostos teóricos e cotidianos da prática escolar, o que ocasionou o engavetamento de todos os testes.

Palavras-chave: Historiografia escolar; Testes ABC; Cultura local.

\section{ABSTRACT}

The aim of this study is to understand the purpose and meaning that the institution's teacher attaches to the existence of ABC Tests at Ipiranga School and, based on it, to speculate on the theoretical assumptions of the New School Movement, the ABC Tests and the applicability of such methodology in the context of the Ipiranga School, Rio Grande do Sul. For that purpose, the book "The ABC Test, a method of verifying the maturity necessary for the learning of reading and writing", school bookkeeping documents and data on the narratives of the teacher who worked at the institution during the period were used as sources of analysis. The tests show a concept of education as a set of techniques required to adapt to the nation's requirements. The 


\section{Tusm \\ ISSN: $1984-6444$

inconsistency of the $\mathrm{ABC}$ tests presence at the school under study indicates resistance from resignified practices and highlights the absence of relation between theoretical and daily assumptions of school practice, which led to the postponement of all tests. Keywords: School historiography; ABC tests; Local culture.

\section{Introdução}

$\mathrm{Na}$ história da educação, as instituições educativas do espaço rural e/ou do campo já foram objeto de análise de diferentes autores, contudo, lacunas específicas em regiões inóspitas geram a possibilidade de, na atualidade, revisitar a historiografia a respeito. O caso da escola em estudo é recolocado a partir da localização de documentos de escrituração escolar. As fontes documentais foram utilizadas na busca pela reconstituição do processo histórico da Escola Ipiranga, escola multisseriada e rural. A localização desse arquivo escolar em análise deriva de processos de Pesquisa e Extensão realizadas pelo Núcleo Educamemória (IE/FURG) junto ao estabelecimento de ensino no interior do município de Pelotas/RS e compõe um acervo de dados de um conjunto maior de documentos encontrados nos arquivos de escolas da região rural da Serra dos Tapes. Os documentos de escrituração escolar que compõe o conjunto do acervo, encontravam-se sob guarda de uma escola nucleada, em razão do fechamento da escola Ipiranga, ocorrido em virtude do processo de nucleação das escolas rurais no Rio Grande do Sul. Os dados específicos desse artigo são, portanto, artefatos culturais da história da educação. As fontes em análise dão conta de apresentar a documentação de uma escola do campo", multisseriada, localizada na região da Serra dos Tapes/RS.

De um conjunto de documentos, apresentamos como fonte primária a presença dos Testes ABC, elaborados por Lourenço Filho, no contexto cotidiano específico da Escola Ipiranga, sua função e aplicabilidade. Nesse movimento de análise,

\footnotetext{
1 Os documentos oficiais denominam esses espaços, em diferentes momentos da história como: Escolas Rurais, Escolas Isoladas, Escolas Multisseriadas. Essas denominações sofrem mudanças a depender do momento histórico ou da legislação vigente. $\mathrm{Na}$ atualidade, esse estabelecimento de ensino seria considerado Escola do Campo, tendo em vista que o mesmo estava localizado dentro de um contexto da agricultura familiar, em sua grande maioria pertencentes ao Povo Pomerano e comunidades quilombolas que são segmentos de Povos e Comunidades Tradicionais (BRASIL, 2007). Para o presente artigo, vamos seguir a denominação oficial dada pela Secretaria Municipal de Educação.
} 


\section{DFn \\ 15SN: 1984-6444

questionamos as relações entre pressupostos que fundamentam os Testes $A B C$ e 0 mundo escolar do campo, considerando, para tanto, relações e distanciamentos entre tendências pedagógicas e práticas educativas no contexto educacional específico da Escola Ipiranga.

Objetivamos recolocar ao tema do movimento da Escola Nova em sua relação com o espaço da escola pública com a pretensão de empreender problematizações acerca dos pressupostos teóricos traçados pelo movimento escolanovista, dos Testes ABC desenvolvidos por Lourenço Filho e da aplicabilidade e concretização de metodologias sugeridas pelo autor no fazer docente em espaço educativo específico. Em outras palavras, pretendemos compreender quais os sentidos atribuídos à presença dos Testes $\mathrm{ABC}$ no contexto da Escola Ipiranga. Para tanto, utilizou-se como fonte de análise o livro Testes $A B C$, para verificação da maturidade necessária à aprendizagem da leitura e da escrita (LOURENÇO FILHO, 1933), e documentos de escrituração escolar, entre eles: Cadernos de Atas e Dados de Matrícula. Apresentamos dados relativos a experiências narradas pela professora que atuava na instituição em estudo no período de aplicação dos Testes ABC. Sujeito representativo do cenário educativo local, que narra, a partir da experiência, como orientou sua prática como professora de escola rural multisseriada. Dessa forma, utilizamos em nossas análises tematizações acerca da entrevista semiestruturada realizada com a docente.

\section{Pressupostos para uma nova escola brasileira}

Em decorrência da autonomia didática proposta pela Reforma Sampaio Dóriae de novas demandas políticas e sociais, a partir de meados da década de 1920, as resistências dos professores frente à utilização do método analítico tomaram novas proporções. Nesse movimento, iniciou-se a busca por novas propostas de solução para os problemas do ensino e aprendizagem iniciais da leitura e escrita. A disputa entre os defensores dos métodos sintéticos e os defensores dos métodos analíticos não cessaram, entretanto, o tom de combate e defesa acirrada que se viu nos momentos anteriores foi-se diluindo gradativamente, à medida que se acentuava a 


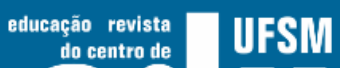

tendência de relativização da importância do método e, mais restritamente, a preferência nesse âmbito pelo método global.

Freire (2005) sustenta que um surto de industrialização envolvia o país, e esse novo arranjo socioeconômico demandava mudanças nas políticas educacionais e nas práticas pedagógicas. Pelos idos de 1930, era urgente a expansão do ensino primário, visto o crescente número de analfabetos que se evidenciava desde a década de 1920 e se intensificava na década seguinte, aumentando a necessidade de se alfabetizar não somente as crianças, mas também os jovens e adultos, que constituiriam a mãode-obra nessa nova fase que principia com o "surto da industrialização". Nesse momento,

[...] o contexto social brasileiro agitava-se em um panorama de transformações mundiais, marcadas por acontecimentos gigantescos, como a Primeira Guerra Mundial (1914-1918), por meio da qual os países desenvolvidos buscavam manter ou constituir seus impérios, e a Revolução Russa (1917) que inaugurou a primeira experiência socialista no mundo (MACHADO, 2009, p. 103).

Outra característica relevante para compreender o contexto da educação no período republicano, é o que Nagle (1978) denomina de "otimismo pedagógico", no qual se introduzia a ideia de que, além de se difundir a instrução pública como "entusiasmo pela educação", era preciso remodelar a escola, ou seja, substituir o modelo já existente por outro, aplicável a uma nova necessidade do mundo do trabalho. Os ideais da Escola Nova, exercitados em espaços de escolas primárias e em espaço de Curso Normal (preparação para o magistério), surgem como uma proposta contrária ao modelo tradicional já implantado.

A consolidação do pensamento republicano dá vazão ao ideal de alguns grupos políticos que consideravam a educação como papel do Estado, nesse sentido, a ideia de "Educação para Todos", como um bem público, passa a ser uma bandeira de luta dos escolanovistas.

As novas contribuições colocadas em voga pelos pioneiros da Escola Nova influenciaram diretamente os métodos que foram desenvolvidos nesse período. Embora singulares em suas características e aplicabilidade, esses métodos emergiram segundo uma necessidade comum: a urgente modificação do ensino brasileiro. Os educadores envolvidos no ideário escolanovista almejavam uma nova 


\section{OF LFH

formação do indivíduo, capaz de questionar e tecer possíveis soluções às problemáticas colocadas, uma vez que "[...] a grande sociedade está para se constituir e o homem deve ser preparado para ser um membro responsável e inteligente desse novo organismo" (TEIXEIRA, 2000, p. 34). Ao passo que defendia os valores e interesses da industrialização da sociedade brasileira, propunha uma nova concepção de métodos de ensino, de programas, de currículos, de organização e administração escolar.

Enquanto a escola tradicional oferecia um ensino descontextualizado e centrado na figura do professor, considerando todos com as mesmas capacidades para aprender, os expoentes da escola nova colocavam as características biológicas do sujeito aprendente como elementos a serem considerados no processo de ensino e aprendizagem. Dessa forma, há o pressuposto de que há formas diversas de apreender conteúdos e conhecimentos. Ensinar a partir dos pressupostos teóricos da escola nova é criar condições de aprendizagens para diferentes sujeitos, com características, tempos e capacidades diferenciadas. Os métodos ativos surgem nesse contexto como necessidade do mundo do trabalho. Ao ensino da leitura e da escrita foi incorporado o aspecto psicológico, em detrimento do pedagógico e linguístico, devendo concretizar-se de forma rápida, econômica e eficaz, atendendo aos objetivos políticos do momento (MORTATTI, 2000). Um "otimismo pedagógico" que postulava o avanço social a partir de um modelo ideal. Qualquer modelo educacional diferenciado do urbano, industrial e patriota era considerado como espaço do atraso cognitiva e cientificamente. Nesse sentido, os múltiplos contextos sociais e econômicos não eram objeto de questionamento dos expoentes do escolanovismo.

Desconsiderando qualquer saber prévio que sujeitos do meio rural poderiam ter e qualquer presença de saberes da cultura local, a promoção da "nova escola brasileira" era uma imposição do modelo urbano sobre o rural, pois aquele deveria servir enquanto modelo de educação de qualidade para toda a nação. A pedagogia urbana foi colocada como imprescindível à formação das novas gerações. Em decorrência, o processo educacional do mundo do campo sofreu alterações, passando a ser elaborado nas referências de mundo urbano e industrial. 


\section{Disn \\ 15SN: 1984-6444

\section{Lourenço Filho e a escola nova: surgimento dos testes $A B C$}

A psicologia experimental aposta que o desenvolvimento de habilidades psicomotoras e experimentações são procedimentos fundamentais para a aprendizagem. Possivelmente, muito antes de apostar em um método de ensino, apostava na produção racional de atitudes e procedimentos capazes de responder a situações desafiantes. Essa tendência de relativização da importância do método de ensino decorreu especialmente da disseminação e institucionalização das então novas e revolucionárias bases psicológicas da alfabetização contidas no livro "Testes $A B C$ para a verificação da maturidade necessária à aprendizagem da leitura e da escrita" (1933), escrito por Manuel Bergström Lourenço Filho.

Buscando compreender as causas do fracasso escolar nos primeiros anos do ensino elementar, Lourenço Filho atuou junto às escolas direcionando seus esforços à elaboração de testes aplicáveis no período inicial da educação escolar. Após realizar pesquisas junto a instituições de ensino, o autor conclui que o fracasso escolar, ou mesmo a dificuldade de aprendizagem dos alunos, decorre de diferenças individuais de nível de maturidade de cada aluno. Tendo esses pressupostos como base do desenvolvimento de seus trabalhos posteriores, Lourenço Filho passa a defender a compreensão de que as aprendizagens realizadas em âmbito escolar devem atender as diferenças individuais dos discentes.

Segundo o teórico, a partir da verificação das potencialidades individuais de cada aluno, a própria escola poderia ser repensada, a começar pela disposição de seu espaço e da organização das classes escolares. As crianças, segundo Lourenço Filho, deveriam ser classificadas conforme seu desempenho intelectual, pois, dessa forma, o processo educativo poderia melhor atender as necessidades do público infantil e auxiliaria na organização da prática docente. Logo, acarretariam em resultados diferenciados ao que dizia respeito ao rendimento e ao fracasso escolar. $O$ trabalho de verificação da maturidade necessária à aprendizagem da leitura e escrita justificava-se à medida que se fazia necessária a superação de problemas estruturais da cultura brasileira, nesse caso, as altas taxas de analfabetismo. A esse respeito coloca o autor: "A questão da leitura e da escrita estava entre os principais problemas; 


\section{DFM

tanto em escolas brasileiras como em outros países, era tão grave que se fazia necessária uma 'transformação radical' do uso da leitura nas escolas" (LOURENÇO FILHO, 1969, p.15).

Para Lourenço Filho, a questão da alfabetização não era o único problema da cultura brasileira - a cultura do povo era elencada como o maior problema da nação, o autor considerava que ao processo de alfabetização deveria ser dispensada a atenção dos professores e demais profissionais de ensino. A criação e utilização dos Testes ABC consistem, no contexto da promulgação dos ideais escolanovistas, em um instrumento essencial para a realização deste trabalho. Conforme Magnani (1997, p.60) os Testes ABC caracterizam-se como

\section{[...] uma espécie de síntese do pensamento inovador e catalisador de Lourenço Filho a respeito do ensino da literatura e escrita, assim como, simultaneamente, das aspirações educacionais características do que consideram o terceiro momento crucial - meados da década de 1920 e meados da década de 1970 - para a constituição da alfabetização como objeto de estudo; [...].}

Os testes apontam para uma concepção de educação como um conjunto de técnicas necessárias às novas gerações para adaptação às exigências e prioridades da nação. A escola apresenta-se como local com função de primar pela socialização, tendo, no período de alfabetização, os instrumentos de aquisição individual de cultura, uma vez que tal período destina-se ao ensino e aprendizagem da escrita e da leitura.Os Testes $A B C$ consistem em oito provas cujo objetivo é medir as habilidades individuais de cada aluno com a finalidade de organizar as turmas escolares de maneira eficiente. São instrumentos organizados a partir dos pressupostos da psicologia experimental articulados ao trato estatístico que visam identificar a variedade mental ao se fundamentar no conceito de maturação. Os testes psicológicos presentes no material de aplicação dos Testes ABC medem habilidades colocadas por seu autor como intrínsecas à aprendizagem da leitura e escrita, a saber: coordenação motora e visomotora, memória motora, memória imediata, memória auditiva, memória lógica, pronunciação, atenção e fatigabilidade.

O material era acompanhado por um guia de avaliação dos resultados dos alunos que previa quatro grupos de resultados. Se o estudante obtivesse 17 pontos ou mais conseguiria ler e escrever ao fim de um semestre letivo sem demonstrar 


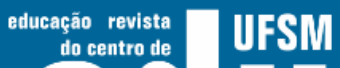

dificuldades ou cansaço. De 12 a 16 pontos a aprendizagem de tais habilidades aconteceria no período do ano letivo. De 8 a 11 pontos o estudante aprenderia a ler e escrever, contudo, exigindo ensino especial, pois apresentaria dificuldades de aprendizagem. Por fim, 0 autor descreve que 0 estudante que obtivesse de 0 a 7 pontos era "retardado" e o ensino comum não lhe serviria.

De um modo geral os Testes ABC buscavam localizar os sujeitos em fase de alfabetização, em agrupamentos, permitindo ao docente estabelecer procedimentos de ensino específicos, buscando assim impactar os dados de evasão e reprovação escolar.

\section{Testes ABC no contexto da Escola Ipiranga: uma relação com o arquivo escolar}

A região em que estava situada a Escola Ipiranga é espaço habitado por imigrantes pomeranos, após 1871. Desse modo, o grupo humano presente na região de abrangência da escola em estudo é descendente do povo pomerano. Os pomeranos mantêm processos ritualísticos, de sociabilidade e de organização social próprios, o que lhes garante continuidade e coesão como grupo cultural. Na atualidade a presença de pomeranos se faz visível no espaço e processos de autoafirmação identitária estão presentes.(THUM, 2009)

De documentos de escrituração escolar da instituição, concentramos nossas análises na presença de sete Testes $A B C$ encontrados junto a documentos de matrícula e rendimento escolar. Tais documentos encontrados no acervo da instituição foram aplicados nos anos de 1981 e 1982. De acordo com a professora que atuava na escola no período de sua aplicação, a presença dos testes nas escolas do município de Pelotas não teve longa duração, o que nos indica que não foram utilizados em outros anos pela instituição.

Originalmente os testes são previstos para serem aplicados no primeiro dia letivo, contudo, ao conversarmos com a professora, percebemos um movimento diferenciado a este respeito. Na Escola Ipiranga, a aplicação desses testes acontecia no ano de ingresso do aluno na instituição, caracterizando-se como atividade a ser 


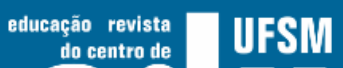 \\ 15SN: 1984-6444

realizada pelo estudante na $1^{\underline{a}}$ série do Ensino Fundamental, mas tal aplicação não ocorria no primeiro dia de aula, nem mesmo na primeira semana.Os testes eram aplicados após o primeiro mês transcorrido de aula, mês denominado pela professora ZC como "mês do período preparatório".

Advindos de uma localidade rural, predominantemente de famílias cuja principal função era o trabalho agrícola, lápis, caderno e giz não eram instrumentos de trabalho presentes no cotidiano das crianças da comunidade local. Essa é uma das razões colocadas pela professora ao nos explicar sobre a necessidade do período preparatório. Atividades de cópia, recorte e colagem eram realizadas com os alunos ingressantes na instituição durante esse primeiro mês de inserção ao espaço escolar, suas normas e práticas. Tais habilidades motoras eram destrezas exigidas pela maioria dos testes que compõem o material de aplicação dos Testes ABC. Embora auxiliasse seus alunos no momento da realização dos Testes $A B C$, atitude não recomendada pelo material de Lourenço Filho, a professora acrescenta ter realizado esse trabalho preparatório porque entendia os mesmos como necessidade para que seus alunos pudessem ter um desempenho mais qualificado nas atividades que Ihes seriam exigidas no período escolar. Quando observado o desempenho de seus alunos na realização dos testes, as notas mais altas encontram-se nas provas que objetivam medir as habilidades de coordenação motora e visomotora e a memória motora, respectivamente os testes de número 1, 7, 8 e 3 .

Ao direcionarmos nossos olhares aos resultados obtidos pelos alunos nos testes de número 2, 4, 5 e 6, observamos uma redução quantitativa em seu desempenho. Para que possamos compreender as razões de tal situação, faz-se necessário analisar aspectos da cultura local e suas relações com as especificidades do fazer docente na classe de alfabetização no contexto da instituição.

As práticas educativas narradas pela professora demonstram a necessidade de ressignificação das atividades propostas ora pela Secretaria Municipal de Educação, ora pelo livro didático de adoção obrigatória, ora pelas provas finais aplicadas por sujeitos externos à instituição e ora pelos Testes $A B C$, uma vez que tais artefatos pedagógicos não correspondiam à realidade imediata do contexto local. Segundo dados tematizados de entrevista realizada com a professora que aplicou os 


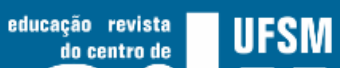 \\ ISSN: 1984-6444

testes, as crianças chegavam à escola "[...] sem saber falar o brasileiro, só sabiam falar o pomerano. Eles não falavam, como iam aprender a ler e escrever o português?" (ZC, 2015). Essa situação é presente também na bibliografia da história da educação e no caso dos pomeranos do Espírito Santo, segundo Bahia (2011, p.102):

[...] Quando estas ingressam na escola, já aprenderam a língua pomerana, fato que ocasiona uma série de conflitos no interior do sistema escolar. Muitas professoras reprimem o uso do pomerano, mas em sua maioria tiveram de aprender um pouco da língua para que pudessem dar continuidade ao seu trabalho na escola.

No caso em análise, a professora não reprimiu o uso do pomerano, ao contrário, a partir do seu uso organizou suas práticas educativas e ensinou a língua portuguesa. As metodologias de trabalho da professora, ao que concerne ao ensino de leitura e escrita, eram elaboradas tendo em vista a especificidade da língua oficial da localidade, considerando a presença de crianças de origem pomerana na escola. Conhecer a língua pomerana e falar fluentemente o idioma, junto ao fato de residir na comunidade Chicuta Oliveira, distrito em que se localizava a escola, foram fatores decisivos para sua permanência como professora regente da Escola Ipiranga durante vinte e cinco anos consecutivos. O fato de conseguir estabelecer comunicação com os alunos auxiliava-a a manter a instituição em funcionamento e a ensinar os conteúdos obrigatórios aos estudantes de maneira compreensível a estes, como é o caso do processo de alfabetização em português. Processos culturais desconsiderados pelo material produzido por Lourenço Filho.

Para realizar os testes, a professora transpunha o significado da escrita em português para a fala em pomerano. Em outras palavras, mostrava aos seus alunos o que estava escrito e qual era a pronúncia correta de acordo com a língua nacional, no caso, o português, e atribuía sentido à palavra ao mostrar qual seria o seu significado na língua oficial da comunidade, o pomerano. A necessidade desse processo de significação do escrito configura-se como uma das razões para que a aplicação dos testes só fosse realizada após o período preparatório e para que a professora os realizasse de maneira diferente das prescritas no guia de exames.

Os testes de número 2, 4, 5 e 6 dependiam, para sua realização, de conhecimento da língua nacional, pois era preciso, em todos eles, embora com fins 


\section{DFM \\ 15SN: 1984-6444

diferenciados, memorizar nomes evocados pelo aplicador dos testes, nesse caso a professora, e repeti-los de forma coerente e clara. "Pindamonhangaba" e "Nabucodonosor", termos presentes na lista de palavras a serem repetidas no teste de número 6, são até hoje lembradas pela professora pelas tentativas que seus alunos realizavam para falar tais expressões, segundo ela: "Saía cada coisa, eles nem sabiam o que estavam falando, eles não sabiam o que significava" (ZC, 2015). A falta de domínio sobre a língua portuguesa e o não reconhecimento de significado nas palavras escritas em português, aliados à dificuldade que os alunos encontravam em pronunciar a língua nacional, por não a conhecer, implicavam na diminuição das notas a serem atribuídas ao seu desempenho durante a realização testes mencionados.

Embora os Testes $A B C$ tenham sido elaborados junto a um rigoroso guia de exames e uma série de recomendações sobre quais posturas e interferências o aplicador dos testes poderia ou não estabelecer com a criança, quando analisamos a prática da professora, encontram-se visíveis alterações das etapas a serem seguidas. A repetição que a professora realizava das palavras a serem memorizadas pelas crianças, o significado atribuído às palavras quando faladas em pomerano e a ajuda frente a possíveis dúvidas dos alunos eram algumas dessas alterações.

Os testes não atendiam as especificidades da realidade local e dissonavam acerca de finalidades propostas pelos Testes $A B C$ e objetivos de ensino da Escola Ipiranga. Os testes prometiam e preconizavam por formação de classes diferenciadas conforme o nível maturacional dos estudantes, entretanto, a multisseriação enquanto presença constante na escola e a atuação de um único docente durante os anos de aplicação das provas não permitiam a concretização dos ideais traçados a partir dos Testes ABC. O "movimento dos testes" visava ao aperfeiçoamento das técnicas de diagnóstico e predição mediante utilização de provas breves e objetivas na forma de questionários passíveis de aplicação em larga escala. Contudo, no caso específico em análise,o objetivo da aplicação dos testes sofria alteração.

Os dados presentes em documentos de escrituração escolar apontam para uma realidade de escola rural isolada, de parca estrutura material e mantida pela ação da professora e da comunidade. A Secretaria Municipal de Educação se fazia presente somente nos atos de oficialização de matrículas e de verificação da 


\section{OF LFH \\ 15SN: 1984-6444

aprendizagem a partir das provas que aplicava. Os Testes $A B C$ vieram somar aos documentos exigidos pela Secretaria. Quando observada a utilização dos testes na prática cotidiana, verifica-se que estes não possuíam utilidade pedagógica nesse contexto. Eram apenas documentos a serem preenchidos e entregues obrigatoriamente à Secretaria Municipal de Educação. Realizado esse protocolo, os testes eram arquivados junto aos documentos dos alunos.

Enquanto fonte histórica, o acervo escolar em análise permite uma compreensão mais alargada de inferência do Estado, no caso representado pela Secretaria Municipal de Educação. Ao direcionar conteúdos e modelar práticas de gestão e práticas pedagógicas, que incluíam a aplicação dos Testes $A B C$, condicionava modos de ser de uma comunidade camponesa. Entre as inferências da Secretaria Municipal de Educação estavam também a indicação de conteúdos a serem utilizados nos processos de ensino e de aprendizagem. As fontes primárias localizadas nesse acervo invariavelmente apresentavam a perspectiva urbana como referência de bem-viver. O mundo rural enquanto contexto não era visualizado, e a cultura local enquanto objeto de ensino era negada.

A presença dos Testes $A B C$ e a comprovação de sua aplicação sem finalidade pedagógica, pois eram arquivados pela escola, demonstra a inadequação da proposta educativa preconizada pelo Estado. Nesse sentido, a proposição inicial preconizada por Lourenço Filho não alcançava seus objetivos no espaço analisado. No que se refere a realidade local, ao não considerar a cultura local como elemento de conhecimento, a educação escolar vivenciada produzia nos educandos uma negação do espaço e da cultura. O rompimento desses condicionamentos se davam por ação da docente, quando a mesma partir de seus saberes pedagógicos, aproximava o ensino à realidade local e desse modo reinventava processos.

\section{Considerações finais}

Empreendemos, neste estudo, o caminho de buscar compreender quais os sentidos atribuídos à presença dos Testes $A B C$ no contexto da Escola Ipiranga, e deparamo-nos com a caracterização, sentidos e significados da aplicação dos testes 


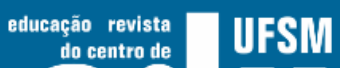 \\ 7 ISSN: 1984-6444

narrados pela professora da instituição como potencial elemento de nossas análises, no sentido de melhor compreendermos a totalidade do contexto sociocultural e histórico que permeia o espaço da comunidade campesina lócus de nossas pesquisas.

Ao revisitarmos os pressupostos teóricos e práticos que compõem a elaboração das provas que constituem os Testes $A B C$ de Lourenço Filho, não há como desconsiderar a contribuição histórica desse material à área de estudos da alfabetização brasileira. A escrita continuou sendo compreendida com ênfase nos processos de desenvolvimento de habilidades caligráfica e ortográfica, que deviam ser ensinadas simultaneamente à habilidade de leitura. A necessidade de período preparatório com exercícios de discriminação visual, coordenação visomotora e auditivo-motora, dentre outros, foi por décadas compreendida como precedente ao aprendizado da leitura e da escrita. Elementos fundantes de uma tradição relacionada ao período da alfabetização: a alfabetização como período de medição. Da mediação da maturidade das crianças a quem se ensina resultam as maneiras de pensar métodos e metodologias de ensino ao que concerne ao aprendizado da escrita e da leitura. Os Testes ABC contribuíram em grande escala para a concretização de tal tradição metodológica. Por esta razão, justifica-se encontrarmos na década de 1980 a presença dos testes na Escola Ipiranga, muito embora tenham sido elaborados e fortemente disseminados no espaço acadêmico e formativo nos anos de 1930.

Lourenço Filho atribui a causa do fracasso escolar às diferenças individuais causadas pelo nível de maturidade de cada criança, todavia, quando analisamos os índices e causas de repetência escolar da escola em análise, encontramos indicadores diferenciados. Conforme Livros de Atas da instituição, o índice de reprovação geral era de $81,5 \%$ na década 1960-1970, o que nos indica índices mais elevados que os nacionais. Naquilo que corresponde ao índice de reprovação brasileiro em meados da década de 1960, este "[...] alcançava aproximadamente 45\% na $1^{\text {a }}$ série. [...]" (OLIVEIRA, 2013, p. 439). O índice de não alfabetizados no período de 1960 a 1969 é de 48\%. É preciso observar que há picos de reprovação consideráveis nesse universo e que estes não sofreram grandes alterações na década que se seguiu. 


\section{Uism \\ 7 ISSN: 1984-6444

A denominação de "não alfabetizados" corresponde a alunos da primeira série que não compareceram à prova final por não estarem alfabetizados, os quais se somam ao índice de repetentes, alcançando um índice quantitativo de metade de "não alfabetizados". Esse índice indica, principalmente, dificuldades no acesso à língua portuguesa e à sua escrita, uma vez que a língua materna da comunidade local era o pomerano. Portanto, os alunos chegavam à escola falando a língua materna e eram obrigados, pela política de língua única, a abandonar o código linguístico da cultura local e incorporar um novo código, oral e gráfico.

Ao revisitarmos os pressupostos teóricos e práticos que compõem a elaboração das provas que constituem os Testes $A B C$ de Lourenço Filho, compreendemos que estes impactaram, em grande escala, estratégias metodológicas e de gestão. Mesmo sendo uma prática datada de meados do século XX, encontrarmos na década de 1980 a presença dos referidos testes na Escola Ipiranga, o que nos indica que seu impacto no tempo e nas políticas educacionais é de longo prazo.

A documentação dos Testes $A B C$ revela práticas educativas da instituição na medida em que pressupõem e orientam concepções epistemológicas de ensino e aprendizagem ao que diz respeito à "[...] verificação da maturidade necessária à aprendizagem da leitura e da escrita". Entretanto, o ensino narrado pela voz da professora nos conta outras faces dessa presença. Indica-nos práticas realizadas apenas por exigência do órgão regulador, no caso, a Secretaria Municipal de Educação. A inadequação da presença dos Testes $A B C$ para com a realidade do contexto educativo local evidenciou a ausência de relações possíveis entre pressupostos teóricos e cotidianos da prática escolar. Essa incompatibilidade ocasionou o procedimento de arquivamento. Institucionalmente um mesmo encaminhamento a todos os testes aplicados: o engavetamento dos resultados.

Embora colocados como obrigatoriedade, como cumprimento de protocolo junto à Secretaria de Educação, encontramos resistências presentes na ressignificação e nas adaptações realizadas pela docente com o objetivo de atender as necessidades e dificuldades apresentadas por seus alunos frente à aplicação dos testes. As escolas do contexto de zona rural, apesar de serem subordinadas às perspectivas da Secretaria de Educação e de uma visão urbana, diferenciavam-se, 


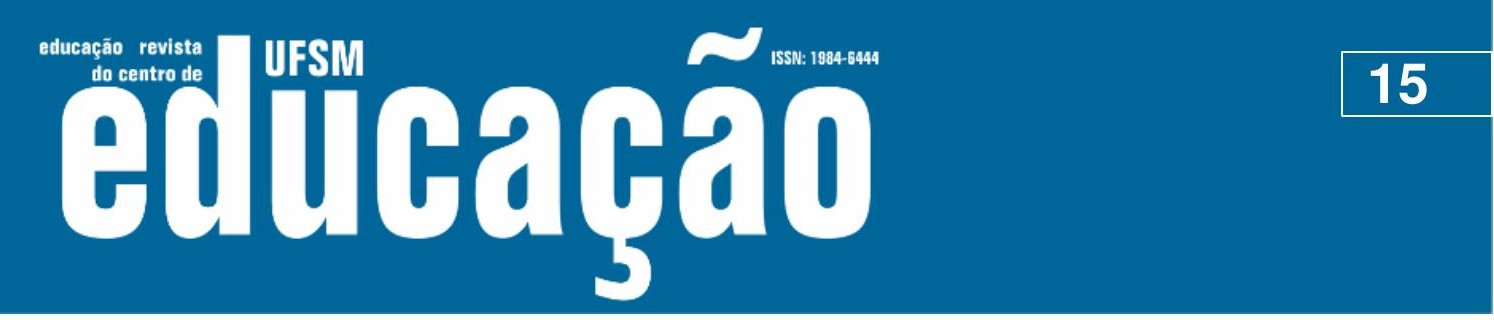

pois, seus professores, em vários casos, resistiam pedagogicamente à medida que construíam suas atividades de forma a configurar o espaço da escola em espaço de manutenção da cultural local. Para tanto, mesclavam em seu fazer obrigatoriedades postas pelo Estado e ações que atendessem os interesses da comunidade étnica local. É possível inferir que tais práticas, reelaboradas em seus sentidos, configuramse enquanto práticas de resistência pedagógica visando à manutenção do espaço da escola como espaço de manutenção da cultura local.

Analisar os dados de acervo escolar de estabelecimentos de ensino como o do caso em estudo possibilita reinterpretar a história da educação. Os dados presentes no acervo, afloram elementos históricos que permitem a escrita da história a partir de uma perspectiva do local. Nesse movimento de reescrita da história novos sentidos e interpretações são possíveis.

\section{Referências}

BAHIA, Joana. O Tiro da Bruxa - Identidade, magia e religião na imigração alemã. Rio de Janeiro: Garamond, 2011.

BRASIL. Decreto 6.040 de 07 de fevereiro de 2007. Disponível em: http://www.planalto.gov.br/ccivil_03/_ato2007-2010/2007/decreto/d6040.htm. Acesso em: 20 de outubro de 2016.

FREIRE, Paulo. Pedagogia do Oprimido. 42 ed. Rio de Janeiro: Paz e Terra, 2005.

LOURENÇO FILHO, Manuel Bergström. O problema da Maturidade para a Leitura e a Escrita. Revista de Educação, 3, 91-100. 1933.

LOURENÇO FILHO, Manuel Bergström. Testes ABC - para a verificação da maturidade necessária à aprendizagem da leitura e da escrita. São Paulo: Melhoramentos, 1969.

MACHADO, Maria Cristina Gomes. Manifesto dos pioneiros da educação nova (1932) e a construção do sistema nacional de ensino no Brasil. In: (AUTOR) (Org.). Fundamentos históricos da educação no Brasil. Maringá. EDUEM 2. Ed. 2009, p.?-?.

MAGNANI, Maria do Rosário Mortatti. Testes ABC e a Fundação de uma Tradição: Alfabetização sob medida. In: MONARCHA, Carlos (Org). Lourenço Filho: outros aspectos, mesma obra. Campinas: Mercado das Letras, 1997, p.59-90.

MORTATTI, Maria do Rosário Longo. Os sentidos da alfabetização. São Paulo: Editora UNESP: CONPED, 2000. 


\section{ussu \\ ISSN: $1984-6444$

NAGLE, Jorge. Educação e Sociedade na primeira república. São Paulo: EPU/Editora da USP, 1978.

OLIVEIRA, Leticia Borges de. Educação no campo e itinerância: uma realidade em Uberlândia/MG. Revista Retratos da Escola, Brasília, v. 7, n. 13, p. 439-451, jul./dez. 2013. Disponível em: <http//www.esforce.org.br>. Acesso em: dia mês abreviado, ano.

TEIXEIRA, Anísio. Pequena introdução à filosofia da educação - a escola Progressiva, ou, a Transformação da escola. 6. ed. Rio de Janeiro: DP\&A, 2000.

\section{Correspondência}

Renata dos Santos Alves - Mestranda no Programa de Pós Graduação em Educação da Universidade Federal de Pelotas, Pelotas, Rio Grande do Sul, Brasil.

Carmo Thum - Professor doutor da Universidade Federal do Rio Grande, Rio Grande, Rio Grande do Sul, Brasil.

Universidade Federal do Rio Grande, Instituto de Educação. Av. Itália, Km 8, Campus Carreiros - Instituto de Educação, Carrreiros. CEP: 96201-900. Rio Grande, Rio Grande do Sul, Brasil.

E-mail: renatasalvees@gmail.com - carthum2004@yahoo.com.br

Recebido em 07 de dezembro de 2016

Aprovado em 23 de outubro de 2017 